\title{
Functional impairment of PRRSV-specific peripheral $\mathrm{CD3}^{+} \mathrm{CD8}^{\text {high }}$ cells
}

\author{
Sarah Costers $^{1 *}$, David J. Lefebvre ${ }^{1}$, Bruno GoddeEris ${ }^{2}$, \\ Peter L. Delputte ${ }^{1}$, Hans J. NauwynCK ${ }^{1}$ \\ ${ }^{1}$ Laboratory of Virology, Department of Virology, Parasitology and Immunology, Faculty of Veterinary Medicine, \\ Ghent University, Salisburylaan 133, 9820 Merelbeke, Belgium \\ ${ }^{2}$ Department of Biosystems, Division of Gene Technology, Faculty of Bioscience Engineering, \\ Catholic University Leuven, Kasteelpark Arenberg 30, 3001 Leuven, Belgium
}

(Received 15 October 2008; accepted 14 May 2009)

\begin{abstract}
The replication of porcine reproductive and respiratory syndrome virus (PRRSV) in lungs and lymphoid tissues of PRRSV-infected pigs is already strongly reduced before the appearance of neutralizing antibodies, indicating that other immune mechanisms are involved in eliminating PRRSV at those sites. This study aimed to determine whether PRRSV Lelystad virus (LV)-specific cytotoxic T-lymphocytes (CTL) can efficiently eliminate PRRSV-infected alveolar macrophages. Therefore, CTL assays were performed with PRRSV-infected alveolar macrophages as target cells and autologous peripheral blood mononuclear cells (PBMC) from PRRSV-infected pigs as a source of PRRSV-specific CTL. PBMC of 3 PRRSV-infected pigs were used either directly in CTL assays, or following restimulation in vitro. CTL assays with pseudorabies virus (PRV) Begonia-infected alveolar macrophages and autologous PBMC, from 2 PRV Begoniainoculated pigs, were performed for validation of the assays. In freshly isolated PBMC, derived from PRRSV-infected pigs, CTL activity towards PRRSV-infected macrophages was not detected until the end of the experiment (56 days post infection - dpi). Restimulating the PBMC with PRRSV in vitro resulted in proliferation of $\mathrm{CD}^{+} \mathrm{CD} 8^{\text {high }}$ cells starting from 14 dpi. Although $\mathrm{CD} 3^{+} \mathrm{CD} 8^{\text {high }}$ cells are generally considered to be CTL, CTL activity was not detected in PRRSV-restimulated PBMC of the 3 pigs until 49 dpi. A weak PRRSV-specific CTL activity was observed only at 56 dpi in PRRSV-restimulated PBMC of one pig. In contrast, a clear CTL activity was observed in PRV Begonia-restimulated PBMC, derived from PRV Begonia-infected pigs, starting from $21 \mathrm{dpi}$. This study indicates that PBMC of PRRSV-infected pigs contain proliferating $\mathrm{CD} 3^{+} \mathrm{CD} 8^{\text {high }}$ cells upon restimulation in vitro, but these PBMC fail to exert CTL activity towards PRRSV-infected alveolar macrophages.
\end{abstract}

PRRSV / cell-mediated immune response / cytotoxic T-lymphocyte / alveolar macrophage

\section{INTRODUCTION}

Porcine reproductive and respiratory syndrome (PRRS) is characterized by reproductive failure in sows and is associated with the respiratory disease complex affecting pigs of all ages $[14,59,60]$. The causative agent, PRRS virus

\footnotetext{
* Corresponding author: sarah.costers@ugent.be
}

(PRRSV), belongs to the family Arteriviridae, order Nidovirales [10]. In vivo, the virus infects subsets of pig macrophages that are mainly present in lungs and lymphoid tissues [20]. The pathogenesis of PRRSV infection is characterized by a high level of viremia for 1 to 2 weeks, followed by a low level of viremia for another 2 to 3 weeks. Subsequently, low levels of PRRSV may persist in lymphoid tissues for

This is an Open Access article distributed under the terms of the Creative Commons Attribution-Noncommercial License (http://creativecommons.org/licenses/by-nc/3.0/), which permits unrestricted use, distribution, and reproduction in any noncommercial medium, provided the original work is properly cited. 
several months [4, 20, 62], but finally, PRRSV is eliminated from most pigs within 2 to 4 months [4, 20, 31, 62]. Up till now, it is not fully elucidated which immune mechanisms cause (i) a drop in virus replication in lungs and lymphoid tissues after 2 weeks of infection, (ii) complete elimination of the virus from the blood after 4 to 5 weeks of infection and (iii) complete elimination of the virus from the lungs and lymphoid tissues within 2 to 4 months.

PRRSV elicits an immune response that differs from the immune response induced by other viral swine pathogens like swine influenza virus or pseudorabies virus (PRV). PRRSVspecific non-neutralizing antibodies are quickly induced starting from 7 days post infection (dpi), but low titres of virus-neutralizing antibodies are only detected starting from 25-35 dpi [31, 37]. In some pigs, low levels of PRRSV replication are still found in lungs and lymphoid tissues in the presence of neutralizing antibodies [31], indicating that other immune mechanisms are involved in the complete elimination of PRRSV at those sites. The adaptive cell-mediated immune response is described to play a critical role in the resolution of many virus infections and is exerted by cytotoxic T-lymphocytes (CTL) and T helper (Th) lymphocytes, in cooperation with Th1-activated natural killer cells (NK) and macrophages. PRRSV infection induces T-lymphocyte mediated immune responses starting from 2 to 4 weeks pi, as assessed by in vitro proliferation assays, in vitro IFN $\gamma$ ELISPOT assays and in vivo delayed type hypersensitivity assays $[7,8,36,41]$. An inversed correlation has been described between the number of $\mathrm{CD}^{+} \mathrm{CD}^{\text {high }}$ cells and PRRSV persistence in lymphoid organs [32]. Therefore, it has been suggested that CTL may play an important role in the reduction of virus replication in lungs and lymphoid tissue after 2 weeks of infection and in the complete clearance of PRRSV infection after 2 to 4 months. However, the contribution of the CTL in the elimination of PRRSVinfected cells has never been investigated. This study aimed to determine whether PRRSVspecific CTL are able to eliminate PRRSVinfected macrophages.

\section{MATERIALS AND METHODS}

\subsection{Viruses}

A 5th passage of PRRSV Lelystad virus (LV) [59, 60] on specific-pathogen-free alveolar macrophages was used for experimental inoculations of pigs. A 13th passage of LV on alveolar macrophages was used for in vitro restimulation of peripheral blood mononuclear cells (PBMC) and for in vitro inoculation of target cells. A PRV vaccine strain was included in this study for validation of the tests: a 2nd passage on swine testicle (ST) cells of PRV Begonia [57] was used for experimental inoculations of pigs, for in vitro restimulation of PBMC and for in vitro inoculation of target cells.

\subsection{Animals and experimental design}

Five 6-week-old pigs from a PRV- and PRRSVnegative farm were used. Alveolar macrophages were collected from each pig, by performing in vivo lung lavages. Briefly, the pigs were completely anesthetized (mixture of Zoletil-100, Virbac Animal Health, Barneveld, Netherlands; and Xyl-M 2\%, VMD, Arendonk, Belgium) and a $40 \mathrm{~cm}$ catheter $(3 \mathrm{~mm}$ diameter) was carefully slid through the trachea into a lung lobe. Lungs were lavaged with phosphatebuffered saline (PBS, $37{ }^{\circ} \mathrm{C}$ ) and the cells obtained were mainly macrophages $(>90 \%)$. The macrophages were aliquoted and stored in liquid $\mathrm{N}_{2}$ until use. At 13 weeks of age, 3 pigs (pigs 1, 2 and 3) were inoculated oronasally with $\mathrm{LV}\left(2 \times 10^{6} \mathrm{TCID}_{50}\right.$ in $8 \mathrm{~mL}$ PBS). Two pigs (pigs 4 and 5) were oronasally inoculated with PRV Begonia $\left(2 \times 10^{7} \mathrm{TCID}_{50}\right.$ in $8 \mathrm{~mL}$ PBS). Blood was sampled at $0,1,3,6,9$, $14,21,28,35,42,49$ and 56 dpi for collection of serum and/or isolation of PBMC. In this study, only a small number of pigs was used for both ethical aspects and the large amount of parameters that had to be examined at the same time. The experiments were approved by the Ethical and Animal welfare Committee of the Faculty of Veterinary Medicine of Ghent University (EC2007/097).

\subsection{Virus isolation and titration and serological examination}

Virus was isolated and titrated from serum or nasal swabs on alveolar macrophages (PRRSV; pigs 1, 2 and 3) or ST cells (PRV Begonia; pigs 4 and 5).

Heat-inactivated sera were tested for the presence of antibodies against PRRSV (pigs 1, 2 and 3) or 
PRV Begonia (pigs 4 and 5) in an immunoperoxidase monolayer assay (IPMA) as described by Wensvoort et al. [59] on respectively methanol-fixed PRRSVinfected Marc-145 cells and methanol-fixed PRV Begonia-infected ST cells. In addition, the sera were tested for the presence of virus-neutralizing antibodies as described by Labarque et al. [31] for PRRSV, and as described by Andries et al. [5] for PRV.

\subsection{Isolation and culture of PBMC for proliferation assays and CTL assays}

PBMC were purified by density centrifugation over Ficoll-Paque (Pharmacia Biotech, Roosendaal, Netherlands). The cells obtained were either paraformaldehyde-fixed for examining proportions of $\mathrm{CD}^{+} \mathrm{CD} 8^{\text {high }}$ cells, either directly used in CTL assays or exposed to recall antigen (virus) in vitro (restimulation) to expand in vivo-primed virus-specific lymphocytes. Prior to restimulation, PBMC were adjusted to a concentration of $4 \times 10^{6}$ viable cells $/ \mathrm{mL}$ medium and seeded in upright $75 \mathrm{~cm}^{2}$ flasks. The medium consisted of a 1:1 mixture of AIM-V serum-free lymphocyte medium (Gibco, Merelbeke, Belgium) and RPMI 1640 medium, supplemented with foetal bovine serum (10\%), L-glutamine $(2 \mathrm{mM})$, non-essential amino acids $(50 \mu \mathrm{M}$ each), sodium pyruvate $(500 \mu \mathrm{M})$, 2-mercaptoethanol $(55 \mu \mathrm{M})$, gentamicin $(50 \mu \mathrm{g} /$ $\mathrm{mL})$, penicillin $(100 \mathrm{U} / \mathrm{mL})$, streptomycin $(100 \mu \mathrm{g} /$ $\mathrm{mL})$. PBMC were restimulated by adding semi-purified [17] cell-free PRRSV (m.o.i. of 1), PRV Begonia (m.o.i. of 1) or mock-control to the cells at one day post seeding. Restimulated PBMC were either used for determination of the amount of lymphocyte proliferation, for determination of proportions of $\mathrm{CD} 3^{+} \mathrm{CD} 8^{\text {high }}$ cells, or used as a source of effector cells in CTL assays.

\subsection{Lymphocyte proliferation assay}

After 5 days of restimulation with virus or mock-control, PBMC were cytocentrifuged, paraformaldehyde-fixed and permeabilized with $0.1 \%$ Triton $\mathrm{X}-100$. In vitro proliferation of in vivo-primed virusspecific $\mathrm{CD} 8^{\text {high }}$ cells was determined by immunofluorescence stainings for both Ki-67 and CD8 antigens. $\mathrm{Ki}-67$ is a short-living nuclear non-histone protein of which the expression is strictly associated with cell proliferation [24]. In short, cell smears were incubated with mAb MONX10284 (Monosan, Uden, Netherlands) directed against Ki-67 and with TexasRed-labeled goat anti-mouse IgG (Molecular Probes, Merelbeke, Belgium). Free goat anti-mouse binding sites were blocked with $10 \%$ mouse serum in PBS. Next, cell smears were incubated with FITC-labeled anti-CD8 $\alpha$ $\mathrm{mAb}$ (76-2-11; Becton Dickinson PharMingen, Erembodegem, Belgium). The stainings were analyzed by fluorescence microscopy. For each condition, at least 2000 PBMC were analyzed. Generally, a CD $8^{\text {high }}$ phenotype is considered to be specific for CTL [46]. Therefore, PBMC that were positive for both $\mathrm{CD} 8^{\text {high }}$ and $\mathrm{Ki}-67$ were considered as proliferating CTL.

\subsection{Flow cytometric analysis of the $\mathrm{CD3}^{+} \mathrm{CD8}^{\text {high }}$ cell subset in mock- and virus-restimulated PBMC}

Paraformaldehyde-fixed PBMC were doublestained for $\mathrm{CD} 3$ and $\mathrm{CD} 8$ by incubating the cells with $\mathrm{mAb}$ against CD3 (BB23-8E6; Becton-Dickinson PharMingen) and with Cy5-labeled goat anti-mouse IgG (Zymed Laboratories, San Francisco, CA, USA). Free goat anti-mouse binding sites were blocked with $10 \%$ mouse serum in PBS. Next, PBMC were incubated with FITC-labeled antiCD8 $\alpha$ mAb (76-2-11; Becton Dickinson PharMingen). At least 10000 cells/sample were analyzed with a Becton-Dickinson FACScanto, equipped with a Sapphire Coherent solid state laser $(488 \mathrm{~nm})$ and a JDS Uniphase HeNe laser (633 nm). FACSDIVA 5.0 software was used for analysis of the samples.

\subsection{CTL assay}

\subsubsection{Target cells}

Autologous alveolar macrophages, obtained by in vivo lung lavages of pigs prior to inoculation, were used as target cells. The cells were cultured for $72 \mathrm{~h}$ prior to inoculation with PRRSV or PRV Begonia at an m.o.i. of 10. At $6 \mathrm{hpi}$, the macrophages were labeled with a fluorescent lipophilic membrane marker, 3,3'-dioctadecyloxacarbocyanine (Dio, Invitrogen). Preliminary analysis showed that this membrane marker had no effect on cell viability and virus replication. At $7 \mathrm{hpi}$, viable macrophages were counted and used as autologous target cells in the CTL assays. The percentage of PRRSV-positive macrophages varied between 30 and $60 \%$; the percentage of PRV Begonia-positive macrophages varied between 70 and $80 \%$.

\subsubsection{Effector cells}

Viable PBMC were counted and used as a source of effector cells. PBMC were either used immediately 
after isolation, or after restimulation with virus for 6 days.

\subsubsection{CTL assay}

Dio-labeled virus-infected alveolar macrophages were seeded in 96-well plates together with serial dilutions of autologous effector cells so that effector:target (E:T) ratios 100:1, 30:1, 0:1 were achieved. Experiments were performed in triplicate. After $4 \mathrm{~h}$ of incubation at $37^{\circ} \mathrm{C}$, cell death was assessed at a single cell level: dead cells were labeled with ethidium bromide monoazide (EMA, Invitrogen), a fluorescent vital dye; the cells were fixed with paraformaldehyde and permeabilized with $0.1 \%$ saponin (Sigma). Virus-infected cells were stained with biotinylated PRRSV-specific polyclonal antibodies [15] or biotinylated PRV-specific polyclonal antibodies [22] and Alexafluor350-labeled streptavidin (Molecular Probes). Dead (EMA-positive) virus-infected target cells were counted using fluorescence microscopy. Cytolytic activity was calculated by subtracting the percentage of dead virus-infected target cells at E:T ratio 0:1 from the percentage of dead virus-infected target cells at E:T ratio's 100:1 or 30:1. MHC-I-restriction of lysis was assessed in two ways: (i) CTL assays were performed with heterologous alveolar macrophages derived by lung lavages of a non-related pig and (ii) CTL assays were performed with virus-infected target cells that were incubated for $30 \mathrm{~min}$ on ice with $\mathrm{mAb}$ directed against MHC-I $(50 \mu \mathrm{g} / \mathrm{mL}$; PT85A, VMRD Inc., Pullman, WA, USA) prior to the CTL assay. The isotype-matched anti-PCV2 mAb 16G12 [34] was used as isotype control in the MHC-I-blocking assay. PRRSV-specificity of observed cytotoxic activity was assessed in CTL assays with PBMC of the PRRSV-infected pigs and autologous alveolar macrophages that were in vitro inoculated with PRV Begonia instead of PRRSV. Similarly, PRV Begoniaspecific cytotoxic activity was determined in CTL assays with PBMC of the PRV Begonia-infected pigs and autologous macrophages that were in vitro infected with PRRSV.

\subsection{Determination of IFN $\gamma$ production by virus- or mock-restimulated PBMC derived from virus-infected pigs}

The supernatant fluids of mock- and virusrestimulated PBMC (6 days of restimulation) were collected for determination of IFN $\gamma$ levels. Therefore, a commercially available IFN $\gamma$ ELISA (Biosource, Merelbeke, Belgium) was used.

\section{RESULTS}

\subsection{Detection of viremia and humoral immune response following exposure to PRRSV or PRV Begonia}

As shown in Figure 1, infectious PRRSV was detected in serum of the 3 PRRSV-inoculated pigs until 14 (pigs 2 and 3) or 21 (pig 1) dpi. On day 9 pi, all 3 PRRSV-infected pigs had seroconverted for PRRSV as shown by IPMA. PRRSV-neutralizing antibodies were detected starting from 21 (pig 3) or 28 (pigs 1 and 2) dpi. PRV Begonia could not be isolated from the PRV Begonia-inoculated pigs, neither from serum, nor from nasal swabs, though the PRV Begonia-inoculated pigs seroconverted for PRV Begonia at 9 dpi and PRV Begoniaspecific neutralizing antibodies were also detected starting from 9 dpi.

\subsection{CTL assay with freshly isolated PBMC}

At $0,7,14,21,28,35,42,49$ and 56 dpi, only negligible levels of cytolytic activity (not more than $4.6 \%$ lysis, average of 3 pigs) towards autologous PRRSV-infected alveolar macrophages were detected in freshly isolated PBMC derived from PRRSV-infected pigs (data not shown). Similar levels of lysis were observed when PRRSV-infected heterologous macrophages or PRV Begonia-infected autologous macrophages were used in the CTL assays (data not shown), indicating that the low level of cytolytic activity was not MHC-I-restricted and not specific for PRRSV.

Similarly, freshly isolated PBMC, derived from PRV Begonia-infected pigs at $0,7,14$, $21,28,35,42,49$ and 56 dpi poorly (not more than $6.4 \%$ lysis) and non-specifically lysed PRV Begonia-infected macrophages in a nonMHC-I-restricted way (data not shown).

\subsection{In vitro proliferation of in vivo-primed virus-specific $\mathrm{CD3}^{+} \mathrm{CD8}^{\text {high }}$ cells}

Since a virus-specific CTL activity was not detected in freshly isolated PBMC, neither for PRRSV, nor for PRV Begonia, PBMC were restimulated in vitro prior to the CTL assay. 

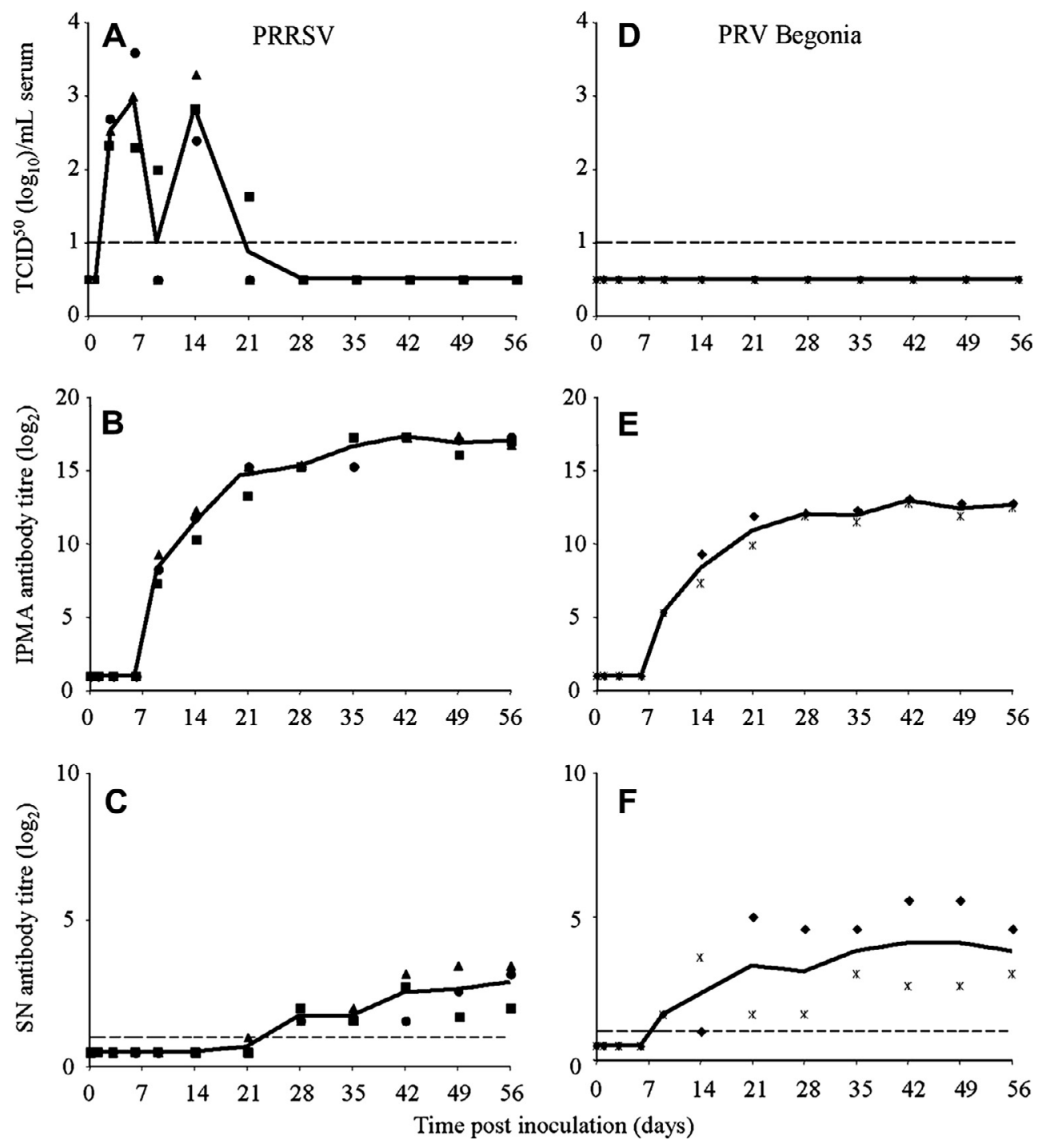

Figure 1. Time course of virus titres (A, D), IPMA antibody titres (B, E) and virus-neutralizing antibody titres $(\mathrm{C}, \mathrm{F})$ in sera of PRRSV-infected pigs (A, B, C) and PRV Begonia-infected pigs (D, E, F). Full symbols represent individual pig values ( $\mathbf{\square}$ pig 1, pig 2, $\boldsymbol{\Delta}$ pig 3, pig 4, * pig 5). Full lines represent average values of the pigs.

As shown in Figure 2, mock-restimulation of PBMC of PRRSV-infected pigs resulted in negligible levels of $\mathrm{CD} 8^{\text {high }}$ cell proliferation until the end of the experiment $(0.0$ to $0.6 \%$ $\mathrm{Ki}-67^{+} \mathrm{CD} 8^{\text {high }}$ cells), with the exception of pig
3 at 42 dpi. Restimulation of the PBMC with PRRSV resulted in a $\mathrm{CD} 8^{\text {high }}$ cell proliferation response starting from $14 \mathrm{dpi}$. This proliferation response increased starting from 42 dpi until the end of the experiment (respectively $3.8 \%, 4.2 \%$ 




Figure 2. Time course of the percentage of proliferating $\mathrm{CD} 8^{\text {high }}$ cells in PBMC that were derived from virus-infected pigs and that were restimulated in vitro with virus or mock-control. A shows data for PRRSVinfected pigs; B for PRV Begonia-infected pigs. Full symbols represent individual pig values after restimulation with virus ( $\mathbf{\square}$ pig $1, \bigcirc$ pig $2, \boldsymbol{\Delta}$ pig $3, \diamond$ pig $4, *$ pig 5); empty symbols represent individual pig values after mock-restimulation ( $\square$ pig 1 , O pig $2, \Delta$ pig $3, \diamond$ pig 4 , x pig 5). Each symbol represents the mean of 3 repetitions in an individual pig; full lines represent average values for the pigs obtained after restimulation with virus; dashed lines represent average values for the pigs obtained after mockrestimulation.

and $4.6 \% \mathrm{Ki}-67^{+} \mathrm{CD} 8^{\text {high }}$ cells at 42,49 and 56 dpi). In the cultures of PRRSV-restimulated PBMC, PRRSV-infected monocytes seemed to be responsible for the presentation of PRRSV antigens via MHC-I towards PRRSV-specific CD $8^{\text {high }}$ cells, since (i) at day 1 of the restimulation, 1 to $2 \%$ of the monocytes was infected with PRRSV; and (ii) restimulation of the PBMC with UV-inactivated PRRSV resulted only in background $\mathrm{CD} 8^{\text {high }}$ cell proliferation levels $(0.5$ to $0.9 \%$; data not shown).

The $\mathrm{CD} 8^{\text {high }}$ cell proliferation response appeared to be PRRSV-specific, since restimulation with PRV Begonia only resulted in background $\mathrm{CD} 8^{\text {high }}$ cell proliferation levels $(0.3$ to $0.8 \% \mathrm{Ki}-67^{+} \mathrm{CD} 8^{\text {high }}$ cells; data not shown).

Restimulation with PRV Begonia of PBMC derived from PRV Begonia-infected pigs resulted in $\mathrm{CD} 8^{\text {high }}$ cell proliferation starting from 14 dpi until the end of the experiment, with maxima at $21 \mathrm{dpi}\left(3.9 \% \mathrm{Ki}-67^{+} \mathrm{CD} 8^{\text {high }}\right.$ cells $)$ and 42 dpi $\left(3.4 \% \mathrm{Ki}-67^{+} \mathrm{CD} 8^{\text {high }}\right.$ cells). This proliferation response was PRV Begoniaspecific since restimulation of these PBMC with PRRSV resulted in background levels of $\mathrm{CD} 8^{\text {high }}$ cell proliferation $(0.2$ to $0.6 \%$ $\mathrm{Ki}-67^{+} \mathrm{CD} 8^{\text {high }}$ cells; data not shown).

\subsection{Flow cytometric analysis of the $\mathrm{CD3}^{+} \mathrm{CD8}^{\text {high }}$ cell subset in virus- or mock-restimulated PBMC}

As shown in Figure 2, in vitro restimulation with virus of PBMC derived from virus-infected pigs resulted in a $\mathrm{CD} 8^{\text {high }}$ cell proliferation response. To evaluate the effect of restimulation on the proportion of $\mathrm{CD}^{+} \mathrm{CD} 8^{\text {high }}$ cells in the PBMC, virus- and mock-restimulated PBMC were stained for $\mathrm{CD} 3$ and $\mathrm{CD} 8$. Restimulation with PRRSV of PBMC derived from PRRSVinfected pigs resulted in an increased percentage of $\mathrm{CD}^{+}{ }^{+} \mathrm{CD} 8^{\text {high }}$ cells starting from $14 \mathrm{dpi} \mathrm{com-}$ pared to mock-restimulation (Fig. 3A).

PRV Begonia restimulation of PBMC derived from PRV Begonia-infected pigs resulted in an increased percentage of $\mathrm{CD}^{+} \mathrm{CD} 8^{\text {high }}$ cells starting from $7 \mathrm{dpi}$, compared to mock-restimulation (Fig. 3B).

\subsection{CTL assay with virus-restimulated PBMC}

Figure 4 shows the percentages of lysed virus-infected target cells at an E:T ratio of 100:1. PRRSV-restimulated PBMC derived from PRRSV-infected pigs possessed no 


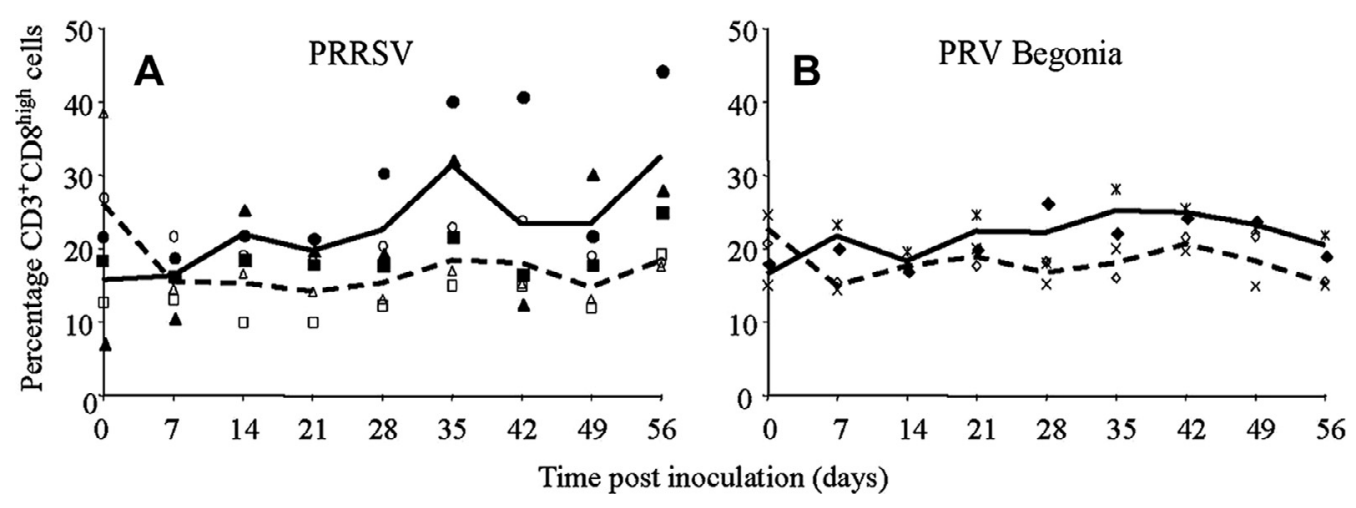

Figure 3. Time course of proportions of $\mathrm{CD} 3^{+} \mathrm{CD} 8^{\text {high }}$ cells in PBMC that were derived from virus-infected pigs and that were in vitro restimulated with virus or mock-control. A shows data for PRRSV-infected pigs; B for PRV Begonia-infected pigs. Full symbols represent individual pig values after restimulation with virus ( $\mathbf{\square}$ pig 1, pig 2, $\mathbf{\Delta}$ pig 3, pig 4, * pig 5); empty symbols represent individual pig values after mockrestimulation ( $\square$ pig 1 , O pig $2, \Delta$ pig $3, \diamond$ pig 4 , x pig 5). Full lines represent average values of the pigs obtained after restimulation with virus. Dashed lines represent average values for the pigs obtained after mock-restimulation.

considerable levels of cytolytic activity towards PRRSV-infected autologous macrophages (2.0 to $8.9 \%$ average lysis of 3 pigs). To evaluate the MHC-I-restriction and the virus-specificity of this low level of cytolysis, 3 controls were used: CTL assays with PRRSV-infected heterologous macrophages, CTL assays with autologous macrophages that were incubated with anti-MHC-I mAb or its isotype control and CTL assays with PRV Begonia-infected autologous macrophages. Compared to each other, these control assays revealed similar levels of target cell lysis, indicating that the negligible levels of lysis were non-MHC-I-restricted and not virus-specific. Only at $56 \mathrm{dpi}$, a low level of PRRSV-specific, MHC-I-restricted cytotoxicity towards PRRSV-infected macrophages was detected in PRRSV-restimulated PBMC of one pig (pig 1).

In contrast, PRV Begonia-restimulated PBMC derived from PRV Begonia-infected pigs lysed PRV Begonia-infected autologous macrophages efficiently (14.5 to $28.1 \%$ average lysis of two pigs) starting from $21 \mathrm{dpi}$. Cytotoxicity towards PRV Begonia-infected autologous macrophages was considerably higher than cytotoxicity towards PRV Begonia-infected heterologous macrophages and than cytotoxicity towards PRV Begonia-infected autologous target cells, incubated with anti-MHC-I mAb. In addition, cytotoxicity towards PRV Begoniainfected autologous macrophages was higher than cytotoxicity towards PRRSV-infected autologous target cells. This indicates that PRV Begonia-restimulated PBMC possess cytolytic activity towards PRV begonia-infected macrophages in a MHC-I-restricted and virusspecific way.

\subsection{Production of IFN $\gamma$ by virus- and mock- restimulated PBMC derived from virus- infected pigs}

In addition to cytolytic activity, the production of IFN $\gamma$ by virus- and mock-restimulated PBMC was also examined. Mock-restimulated PBMC derived from PRRSV-inoculated pigs at 0 to $56 \mathrm{dpi}$, produced negligible amounts of IFN $\gamma$ (Fig. 5). The average amount of IFN $\gamma$ produced by PRRSV-restimulated PBMC derived from PRRSV-infected pigs at $0 \mathrm{dpi}$ was remarkably high $\left(726\right.$ pg per $4 \times 10^{6}$ cells) compared to the average amount of IFN $\gamma$ produced by PRV Begonia-restimulated PBMC derived from the PRV Begonia-infected pigs at 0 dpi (193 pg per $4 \times 10^{6}$ cells). This high 

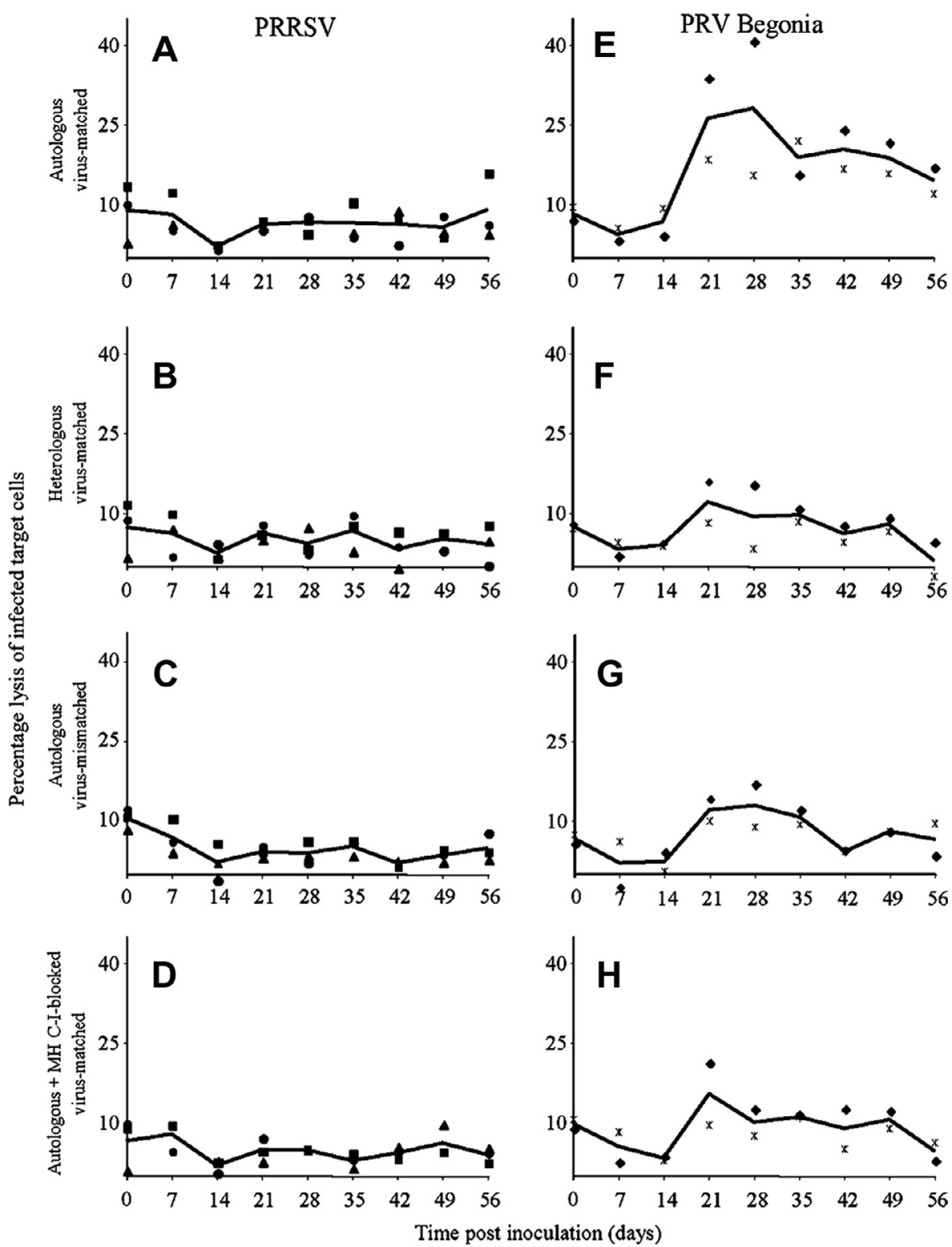

Figure 4. Time course of cytolytic activity of virus-restimulated PBMC (derived from virus-infected pigs) towards autologous virus-infected macrophages $(\mathrm{A}, \mathrm{E})$, towards heterologous virus-infected macrophages $(B, F)$, towards autologous macrophages that were infected with another virus $(C, G)$ or towards autologous virus-infected macrophages, that were incubated with anti-MHC-I antibodies (D, H). A, B, C and D show data for PRRSV-infected pigs; E, F, G and H show data for PRV Begonia-infected pigs. Full symbols represent individual pig values ( $\boldsymbol{\square}$ pig 1 , $\bigcirc$ pig $2, \boldsymbol{\Delta}$ pig $3, \diamond$ pig $4, *$ pig 5 ). Each symbol represents the mean of 3 repetitions in an individual pig. Full lines represent average values of the pigs. 


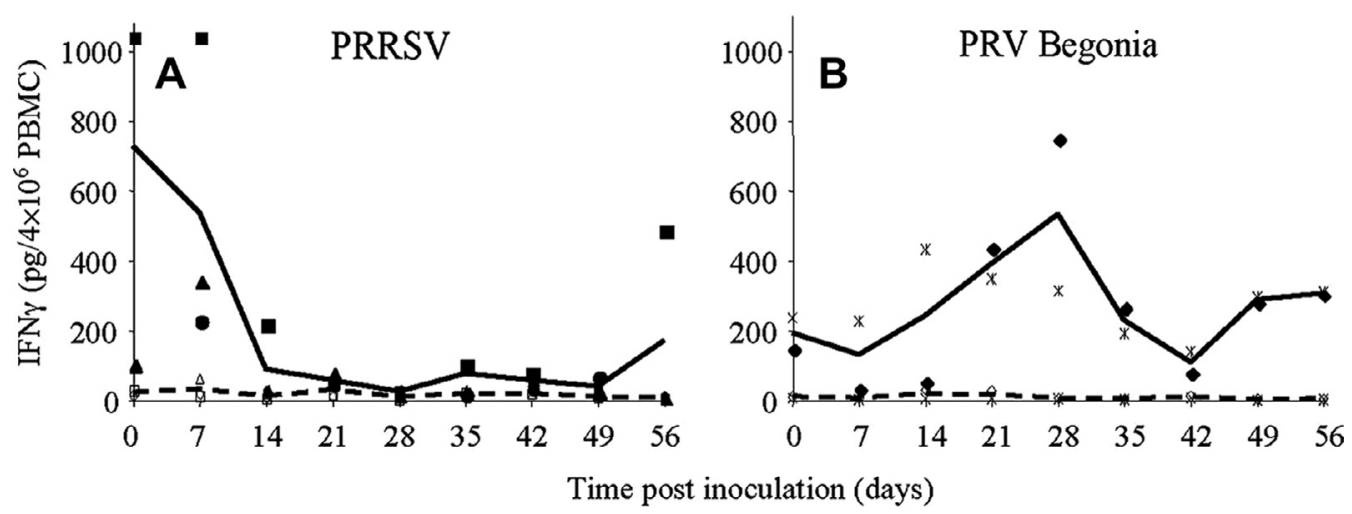

Figure 5. Time course of IFN $\gamma$ production by virus-restimulated or mock-restimulated PBMC that were derived from virus-infected pigs. A shows data for PRRSV-infected pigs; B for PRV Begonia-infected pigs. Full symbols represent individual pig values of IFN $\gamma$ production by PBMC after restimulation with virus ( $\operatorname{aig~1,~pig~2,~} \boldsymbol{\Delta}$ pig 3, pig 4,* pig 5); empty symbols represent individual pig values of IFN $\gamma$ production by PBMC after mock-restimulation ( $\square$ pig 1 , O pig $2, \Delta$ pig $3, \diamond$ pig 4 , x pig 5). Full lines represent average values for the pigs obtained after restimulation with virus. Dashed lines represent average values for the pigs obtained after mock-restimulation.

average value was caused by the high IFN $\gamma$ production of the PBMC of pigs 1 and 2 (both 1040 pg per $4 \times 10^{6}$ cells). The general IFN $\gamma$ production was strongly reduced at later time points until the end of the experiment, except for pig 1, whose PBMC still produced high amounts of IFN $\gamma$ at $7 \mathrm{dpi}$, and again at $56 \mathrm{dpi}$. Mock-restimulated PBMC derived from PRV Begonia-inoculated pigs at 0 to 56 dpi produced negligible amounts of IFN $\gamma$. PRV Begoniarestimulated PBMC derived from PRVinoculated pigs produced IFN $\gamma$ at all examined time points. The highest IFN $\gamma$ levels were produced by restimulated PBMC that were isolated from the pigs at 21 and 28 dpi (respectively 392.0 and 521.5 pg per $4 \times 10^{6}$ cells).

\section{DISCUSSION}

PRRSV replicates to high levels in lungs and lymphoid tissues, resulting in an extensive viremia during 2 weeks. Afterwards, the virus replicates at low levels for several weeks more. In some pigs, virus may persist for months, despite the presence of neutralizing antibodies $[7,31]$. Until now, the role of CTL in the control of
PRRSV replication was not investigated. In this study, CTL assays were performed with freshly isolated or PRRSV-restimulated PBMC derived from PRRSV-infected pigs as source of PRRSV-specific CTL and autologous PRRSVinfected alveolar macrophages as target cells.

Previously, Kawashima et al. [28] reported an increased number of $\mathrm{CD}^{+} \mathrm{T}$-lymphocytes in periarteriolar lymphoid sheets of the spleen and in the paracortex of superficial inguinal lymph nodes of PRRSV-infected pigs, starting from $10 \mathrm{dpi}$. Other studies describe an influx of $\mathrm{CD}^{+}$T-lymphocytes in the blood, lungs and medial retropharyngeal lymph nodes of infected pigs, starting from 10 to $24 \mathrm{dpi}$ $[3,33,49,50]$. This suggests that PRRSVspecific $\mathrm{CD}^{+}$T-lymphocytes migrate from lymphoid sites of initial activation to sites of antigen deposition. Upon infection with PRRSV, an increased proportion of $\mathrm{CD} 3^{+} \mathrm{CD} 8^{\text {high }}$ cells in freshly isolated PBMC was also observed in this study (data not shown), but CTL activity towards PRRSV-infected macrophages was not detected in these freshly isolated PBMC (data not shown). CTL activity was also not detected in freshly isolated PBMC derived from PRV Begoniainfected pigs in accordance with a study of De Bruin et al. [16]. Most likely, this is due to 
a low number of virus-specific CTL in the peripheral blood at the time points of blood collection $[16,21]$. The sample time point appears to be a critical factor for the detection of direct CTL effector activity in the peripheral blood, since specific effector CTL are present in the blood for only a short period of time (own observation by B. Goddeeris).

Restimulating PBMC, derived from PRRSV-infected pigs, with PRRSV in vitro resulted in proliferation of $\mathrm{CD} 8^{\text {high }}$ cells starting from $14 \mathrm{dpi}$, and in an increased proportion of $\mathrm{CD}^{+} \mathrm{CD} 8^{\text {high }}$ cells. However, PRRSVspecific MHC-I-restricted cytolytic activity towards PRRSV-infected macrophages was not detected in these PBMC, except for pig 1 at 56 dpi. In contrast, PRV Begonia-restimulated PBMC derived from PRV Begonia-infected pigs possessed a clear CTL activity towards PRV Begonia-infected macrophages, which proves the well-functioning of the CTL assay technique used. Different hypotheses can be formulated to explain the observed lack of CTL activity: either (i) PRRSV-infected macrophages are not recognized by CTL, or (ii) PRRSV-infected macrophages are resistant to CTL-mediated lysis, or (iii) the responding $\mathrm{CD}^{+}{ }^{+} \mathrm{CD} 8^{\text {high }}$ cells are not PRRSV-specific CTL, or (iv) PRRSV-specific CTL are functionally impaired.

CTL recognize virus-infected cells via surface MHC-I molecules carrying viral peptides. In order to escape CTL-mediated lysis, many viruses have evolved strategies to interfere with the MHC-I pathway [26]. In this study, downregulation of surface MHC-I molecules was not observed in PRRSV-positive macrophages (data not shown). However, whether PRRSV peptides were loaded onto the MHC-I molecules was not determined.

CTL eliminate their target cells by inducing apoptosis via the death receptor-mediated and/ or the granzyme-mediated apoptosis pathway. Many viruses have developed strategies to interfere with these apoptosis pathways to protect infected cells against CTL-mediated elimination [6]. In this study, PRRSV-infected target cells were susceptible to lytic activity exerted by PRV Begonia-restimulated PBMC derived from PRV Begonia-infected pigs. This suggests that PRRSV-infected macrophages are not resistant to death receptor and/or granzymeinduced apoptosis, since it demonstrates susceptibility of PRRSV-infected macrophages towards NK activity, which is also exerted via death receptor and/or granzyme-induced apoptosis [27].

It cannot be excluded that the proliferating $\mathrm{CD} 3^{+} \mathrm{CD} 8^{\text {high }}$ cells that were only detected upon restimulation with PRRSV, are not PRRSV-specific CTL. In vitro restimulation with PRRSV induced $\mathrm{CD}^{+}$T-lymphocyte proliferation ( 7 to $15 \%$ proliferating $\mathrm{CD} 4^{+}$cells; data not shown), which may have induced aspecific cytokine-mediated proliferation of $\mathrm{CD}^{+} \mathrm{CD} 8^{\text {high }}$ cells as a bystander effect [54].

It is also possible that the observed proliferating $\mathrm{CD}^{+} \mathrm{CD} 8^{\text {high }}$ cells are PRRSV-specific CTL, but with an impaired effector function. Functional impairment of CTL is a common viral immune evasion mechanism and several virus-mediated mechanisms causing CTL impairment have been described $[1,9,25,30$, 39, 43, 45, 47, 64]. Dendritic cells, which are the most important antigen-presenting cells, play a crucial role in the activation of naïve CTL [27]. Some viruses, like herpes simplex virus-1, human cytomegalovirus and hepatitis $B$ virus, can render dendritic cells ineffective in stimulating T-lymphocytes [9, 43, 47]. Recent in vitro studies show that PRRSV replicates in certain subsets of dendritic cells, downregulates MHC-I, MHC-II and CD80/CD86 surface expression in these cells and induces dendritic cell apoptosis and necrosis at the end of the replication cycle [11, 23, 38, 58]. Up till now, it is not known whether these findings also account for the in vivo situation. Nevertheless, they suggest that PRRSV impairs the dendritic cell-mediated antigen-presenting function towards naïve $\mathrm{CD}^{+}$T-lymphocytes, which may result in an aberrant stimulation of naïve $\mathrm{CD}^{+}$T-lymphocytes and an aberrant CTL development. In addition to antigen and co-stimulation, $\mathrm{CD}^{+}$T-lymphocytes require cytokines like IFN $\alpha$ and IL12 for optimal generation of effector and memory cells [42]. However, PRRSV replication does not induce or even suppresses significant IFN $\alpha$ production $[2,56]$, which also might contribute to an aberrant CTL development. 
CTL impairment can also be caused by the continuous presence of viral antigen and the consequent continuous activation of virusspecific immune cells which results in functional exhaustion or even physical depletion of virus-specific CTL clones [61, 64], or in a general CTL suppression by the induction of regulatory T-lymphocytes $[39,48,55]$. PRRSV can persist in PRRSV-infected pigs for several months $[4,20,31,62]$, thereby possibly stimulating PRRSV-specific immune cells for an extended period. Similarly to what is observed in chronic lymphocytic choriomeningitis virus and human immunodeficiency virus infections $[30,64]$, it is possible that virus-specific proliferating, but regulatory T-lymphocyte-mediated functionally impaired $\mathrm{CD} 3^{+} \mathrm{CD} 8^{\text {high }}$ cells are also present during PRRSV infection. This hypothesis is in agreement with the recently described PRRSV-mediated induction of regulatory T-lymphocytes [51], and by the fact that PRRSV stimulates the production of IL10 $[11-13,19,23,52,53]$, which is known to be involved in the induction of regulatory T-lymphocytes [35].

In this study, CTL activity was not detected in PBMC of pigs that were infected with the PRRSV LV strain. It is known that different PRRSV strains may induce differences in immune responses [19, 29, 40]. Whether the observations made in this study also account for PRRSV strains that are different from LV, remains to be determined.

Upon virus infection, the host immune response is generally directed into a Th1 response that is specialized in eliminating intracellular pathogens [27]. One of the key cytokines of a Th1 response is IFN $\gamma$, which is produced by innate immune effector cells like NK, $\gamma \delta$ T-lymphocytes and macrophages, and by cells of the adaptive immunity, like CD4 Th1 lymphocytes, CTL and memory lymphocytes [27]. At 0 dpi, clear IFN $\gamma$ levels were detected in supernatants of both PRRSVrestimulated PBMC of pigs 1 and 2, and in PRV Begonia-restimulated PBMC of pigs 4 and 5. Surprisingly, the IFN $\gamma$ levels were higher for pigs 1 and 2 than for pigs 4 and 5. It is unlikely that the high IFN $\gamma$ level is caused by PRRSV, since PRRSV restimulation of PBMC of pig 4 did not result in high IFN $\gamma$ levels. Most probably, the initial high IFN $\gamma$ levels are rather due to host-associated factors. After $14 \mathrm{dpi}$, only negligible levels of IFN $\gamma$ were detected in supernatants of PRRSV-restimulated PBMC of PRRSV-infected pigs, except for pig 1 at $56 \mathrm{dpi}$, whereas clear IFN $\gamma$ levels were observed in supernatants of PRV Begoniarestimulated PBMC of PRV Begonia-infected pigs. The lack of CTL activity and the lack of IFN $\gamma$ production in PRRSV-restimulated PBMC derived from PRRSV-infected pigs suggest an impaired Th1 response upon infection with PRRSV. Our data support previous reports on PRRSV-induced cell-mediated immunity in which only low frequencies of PRRSV-specific IFN $\gamma$-secreting cells were detected in PBMC of PRRSV-infected pigs during the first 2 months pi $[7,18,41,63]$.

The role of the PRRSV-specific cellmediated immune response in the final resolution of PRRSV infection remains unclear. Some studies indicate that the PRRSV-specific cell-mediated immunity, as assessed by IFN $\gamma$ secreting cells, has the potential to protect pigs from PRRSV infection [65]. However, the lack of CTL activity detection does not support the idea of an important role of PRRSV-specific CTL in the clearance of PRRSV infection. It is likely that the present in vitro findings also count for the in vivo situation, since PRRSVpositive cells are still present in lungs of PRRSV-infected pigs at 35 dpi despite a clear $\mathrm{CD}^{+} \mathrm{CD} 8^{\text {high }}$ influx in the lungs starting from 10 dpi $[31,49]$. The functionality of PRRSVspecific CTL might be restored at later time points, e.g. once the virus load has declined beyond a certain threshold, as described previously [64]. In accordance with this, Meier et al. [41] demonstrated that higher levels of PRRSVspecific IFN $\gamma$-secreting cells only appeared starting from 25 weeks pi. The CTL activity and IFN $\gamma$ production that were observed in pig 1 at 56 dpi also support this assumption.

Most likely, besides PRRSV-neutralizing antibodies and PRRSV-specific CTL, other (immune) mechanisms are involved in controlling and clearing PRRSV infection. PRRSV-restimulated PBMC of pig 1 possessed virus-non-specific and non-MHC-I-restricted 
cytolytic activity at 0 and 7 dpi and produced high levels of IFN $\gamma$ at those time points. Most likely, the cytolytic activity and the IFN $\gamma$ production were caused by innate immune effector cells, like NK cells or $\gamma \delta$ T-lymphocytes, in PBMC of that pig. Starting from day 0 pi until the end of the experiment, freshly isolated PBMC of pig 1 possessed 10 to $20 \%$ more $\gamma \delta$ T-lymphocytes than the other two PRRSVinfected pigs (data not shown). Whether $\gamma \delta$ T-lymphocytes were responsible for the cytotoxic effect and the IFN $\gamma$ production in vitro was not investigated but some data in this study, such as an inversed correlation between viremia and the amount of $\gamma \delta$ T-lymphocytes in freshly isolated PBMC (data not shown), support this assumption. Several studies also suggest a role for the $\gamma \delta$ T-lymphocyte-mediated non-MHCI-restricted cytolytic activity in resolution of PRRSV infection [7, 36, 44]. However, up till now, there is no sufficient evidence to consolidate this.

In the present study, proliferation of $\mathrm{CD}^{+} \mathrm{CD} 8^{\text {high }}$ cells was induced in PBMC upon restimulation with PRRSV. However, neither PRRSV-specific CTL activity, nor IFN $\gamma$ production was detected in these PBMC, indicating that the PBMC did not possess PRRSV-specific CTL activity. It remains to be determined whether there is PRRSV-specific CTL activity in vivo, but functional impairment or absence of PRRSV-specific CTL in vivo may play a role in the prolonged presence of PRRSV in its host.

Acknowledgements. The authors would like to thank Carine Boone, Lieve Sys, Nele Dennequin, Melanie Bauwens and Chantal Vanmaercke for their excellent technical assistance. S. Costers is supported by a doctoral grant from the special research fund of Ghent University (011D18904). D. Lefebvre receives a "Dehousse"-grant from Ghent University, funded by the Sixth Framework Programme of the European Union. P.L. Delputte is a post-doctoral fellow of the Fund for Scientific Research Flanders (FWO).

\section{REFERENCES}

[1] Aandahl E.M., Michaelsson J., Moretto W.J., Hecht F.M., Nixon D.F., Human CD4+ CD25+ regulatory $\mathrm{T}$ cells control T-cell responses to human immunodeficiency virus and cytomegalovirus antigens, J. Virol. (2004) 78:2454-2459.

[2] Albina E., Carrat C., Charley B., Interferon-alpha response to swine arterivirus (PoAV), the porcine reproductive and respiratory syndrome virus, J. Interferon Cytokine Res. (1998) 18:485-490.

[3] Albina E., Piriou L., Hutet E., Cariolet R., L'Hospitalier R., Immune responses in pigs infected with porcine reproductive and respiratory syndrome virus (PRRSV), Vet. Immunol. Immunopathol. (1998) 61:49-66.

[4] Allende R., Laegreid W.W., Kutish G.F., Galeota J.A., Wills R.W., Osorio F.A., Porcine reproductive and respiratory syndrome virus: description of persistence in individual pigs upon experimental infection, J. Virol. (2000) 74:10834-10837.

[5] Andries K., Pensaert M.B., Vandeputte J., Effect of experimental infection with pseudorabies (Aujeszky's disease) virus on pigs with maternal immunity from vaccinated sows, Am. J. Vet. Res. (1978) 39:1282-1285.

[6] Aubert M., Jerome K.R., Apoptosis prevention as a mechanism of immune evasion, Int. Rev. Immunol. (2003) 22:361-371.

[7] Batista L., Pijoan C., Dee S., Olin M., Molitor T., Joo H.S., et al., Virological and immunological responses to porcine reproductive and respiratory syndrome virus in a large population of gilts, Can. J. Vet. Res. (2004) 68:267-273.

[8] Bautista E.M., Molitor T.W., Cell-mediated immunity to porcine reproductive and respiratory syndrome virus in swine, Viral Immunol. (1997) 10:83-94.

[9] Beckebaum S., Cicinnati V.R., Zhang X., Ferencik S., Frilling A., Grosse-Wilde H., et al., Hepatitis B virusinduced defect of monocyte-derived dendritic cells leads to impaired Thelper type 1 response in vitro: mechanisms for viral immune escape, Immunology (2003) 109: 487-495.

[10] Cavanagh D., Nidovirales: a new order comprising Coronaviridae and Arteriviridae, Arch. Virol. (1997) 142:629-633.

[11] Chang H.C., Peng Y.T., Chang H.L., Chaung H.C., Chung W.B., Phenotypic and functional modulation of bone marrow-derived dendritic cells by porcine reproductive and respiratory syndrome virus, Vet. Microbiol. (2008) 129:281-293.

[12] Charerntantanakul W., Platt R., Johnson W., Roof M., Vaughn E., Roth J.A., Immune responses and protection by vaccine and various vaccine adjuvant candidates to virulent porcine reproductive and 
respiratory syndrome virus, Vet. Immunol. Immunopathol. (2006) 109:99-115.

[13] Chung H.K., Chae C., Expression of interleukin10 and interleukin-12 in piglets experimentally infected with porcine reproductive and respiratory syndrome virus (PRRSV), J. Comp. Pathol. (2003) 129:205-212.

[14] Collins J.E., Benfield D.A., Christianson W.T., Harris L., Hennings J.C., Shaw D.P., et al., Isolation of swine infertility and respiratory syndrome virus (isolate ATCC VR-2332) in North America and experimental reproduction of the disease in gnotobiotic pigs, J. Vet. Diagn. Invest. (1992) 4:117-126.

[15] Costers S., Delputte P.L., Nauwynck H.J., Porcine reproductive and respiratory syndrome virusinfected alveolar macrophages contain no detectable levels of viral proteins in their plasma membrane and are protected against antibody-dependent, complement-mediated cell lysis, J. Gen. Virol. (2006) 87: 2341-2351.

[16] De Bruin M.G., De Visser Y.E., Kimman T.G., Bianchi A.T., Time course of the porcine cellular and humoral immune responses in vivo against pseudorabies virus after inoculation and challenge: significance of in vitro antigenic restimulation, Vet. Immunol. Immunopathol. (1998) 65:75-87.

[17] Delputte P.L., Vanderheijden N., Nauwynck H.J., Pensaert M.B., Involvement of the matrix protein in attachment of porcine reproductive and respiratory syndrome virus to a heparinlike receptor on porcine alveolar macrophages, J. Virol. (2002) 76:4312-4320.

[18] Diaz I., Darwich L., Pappaterra G., Pujols J., Mateu E., Immune responses of pigs after experimental infection with a European strain of porcine reproductive and respiratory syndrome virus, J. Gen. Virol. (2005) 86:1943-1951.

[19] Diaz I., Darwich L., Pappaterra G., Pujols J., Mateu E., Different European-type vaccines against porcine reproductive and respiratory syndrome virus have different immunological properties and confer different protection to pigs, Virology (2006) 351: 249-259.

[20] Duan X., Nauwynck H.J., Pensaert M.B., Virus quantification and identification of cellular targets in the lungs and lymphoid tissues of pigs at different time intervals after inoculation with porcine reproductive and respiratory syndrome virus (PRRSV), Vet. Microbiol. (1997) 56:9-19.

[21] Even C., Rowland R.R., Plagemann P.G., Cytotoxic $\mathrm{T}$ cells are elicited during acute infection of mice with lactate dehydrogenase-elevating virus but disappear during the chronic phase of infection, J. Virol. (1995) 69:5666-5676.
[22] Favoreel H.W., Nauwynck H.J., Van Oostveldt P., Mettenleiter T.C., Pensaert M.B., Antibody-induced and cytoskeleton-mediated redistribution and shedding of viral glycoproteins, expressed on pseudorabies virus-infected cells, J. Virol. (1997) 71:8254-8261.

[23] Flores-Mendoza L., Silva-Campa E., Resendiz M., Osorio F.A., Hernandez J., Porcine reproductive and respiratory syndrome virus infects mature porcine dendritic cells and up-regulates interleukin-10 production, Clin. Vaccine Immunol. (2008) 15:720-725.

[24] Gerdes J., Schwab U., Lemke H., Stein H., Production of a mouse monoclonal antibody reactive with a human nuclear antigen associated with cell proliferation, Int. J. Cancer (1983) 31:13-20.

[25] Grakoui A., John Wherry E., Hanson H.L., Walker C., Ahmed R., Turning on the off switch: regulation of anti-viral $\mathrm{T}$ cell responses in the liver by the PD-1/PD-L1 pathway, J. Hepatol. (2006) 45: $468-472$.

[26] Hewitt E.W., The MHC class I antigen presentation pathway: strategies for viral immune evasion, Immunology (2003) 110:163-169.

[27] Janeway C.A., Travers P., Walport M., Schlomchik M., Immunobiology, the immune system in health and disease, 6th edn., Garland Science Publishing, New York, USA, 2005.

[28] Kawashima K., Narita M., Yamada S., Changes in macrophage and lymphocyte subpopulations of lymphoid tissues from pigs infected with the porcine reproductive and respiratory syndrome virus (PRRSV), Vet. Immunol. Immunopathol. (1999) 71: 257-262.

[29] Kim W.I., Lee D.S., Johnson W., Roof M., Cha S.H., Yoon K.J., Effect of genotypic and biotypic differences among PRRS viruses on the serologic assessment of pigs for virus infection, Vet. Microbiol. (2007) 123:1-14.

[30] Kinter A.L., Horak R., Sion M., Riggin L., McNally J., Lin Y., et al., CD25+ regulatory T cells isolated from HIV-infected individuals suppress the cytolytic and nonlytic antiviral activity of HIV-specific CD8+ T cells in vitro, AIDS Res. Hum. Retroviruses (2007) 23:438-450.

[31] Labarque G.G., Nauwynck H.J., Van Reeth K., Pensaert M.B., Effect of cellular changes and onset of humoral immunity on the replication of porcine reproductive and respiratory syndrome virus in the lungs of pigs, J. Gen. Virol. (2000) 81:1327-1334.

[32] Lamontagne L., Page C., Larochelle R., Longtin D., Magar R., Polyclonal activation of B cells occurs in lymphoid organs from porcine reproductive and respiratory syndrome virus (PRRSV)-infected pigs, Vet. Immunol. Immunopathol. (2001) 82:165-182. 
[33] Lamontagne L., Page C., Larochelle R., Magar R., Porcine reproductive and respiratory syndrome virus persistence in blood, spleen, lymph nodes, and tonsils of experimentally infected pigs depends on the level of CD8high T cells, Viral Immunol. (2003) 16:395-406.

[34] Lefebvre D.J., Costers S., Van Doorsselaere J., Misinzo G., Delputte P.L., Nauwynck H.J., Antigenic differences among porcine circovirus type 2 strains, as demonstrated by the use of monoclonal antibodies, J. Gen. Virol. (2008) 89:177-187.

[35] Levings M.K., Bacchetta R., Schulz U., Roncarolo M.G., The role of IL-10 and TGF-beta in the differentiation and effector function of $\mathrm{T}$ regulatory cells, Int. Arch. Allergy Immunol. (2002) 129: 263-276.

[36] Lopez Fuertes L., Domenech N., Alvarez B., Ezquerra A., Dominguez J., Castro J.M., Alonso F., Analysis of cellular immune response in pigs recovered from porcine respiratory and reproductive syndrome infection, Virus Res. (1999) 64:33-42.

[37] Lopez O.J., Osorio F.A., Role of neutralizing antibodies in PRRSV protective immunity, Vet. Immunol. Immunopathol. (2004) 102:155-163.

[38] Loving C.L., Brockmeier S.L., Sacco R.E., Differential type I interferon activation and susceptibility of dendritic cell populations to porcine arterivirus, Immunology (2007) 120:217-229.

[39] Mahic M., Henjum K., Yaqub S., Bjornbeth B.A., Torgersen K.M., Tasken K., Aandahl E.M., Generation of highly suppressive adaptive CD8(+) $\mathrm{CD} 25(+) \mathrm{FOXP} 3(+)$ regulatory $\mathrm{T}$ cells by continuous antigen stimulation, Eur. J. Immunol. (2008) 38: 640-646.

[40] Mateu E., Diaz I., The challenge of PRRS immunology, Vet. J. (2008) 177:345-351.

[41] Meier W.A., Galeota J., Osorio F.A., Husmann R.J., Schnitzlein W.M., Zuckermann F.A., Gradual development of the interferon-gamma response of swine to porcine reproductive and respiratory syndrome virus infection or vaccination, Virology (2003) 309:18-31.

[42] Mescher M.F., Curtsinger J.M., Agarwal P., Casey K.A., Gerner M., Hammerbeck C.D., et al., Signals required for programming effector and memory development by CD $8+\mathrm{T}$ cells, Immunol. Rev. (2006) 211:81-92.

[43] Moutaftsi M., Mehl A.M., Borysiewicz L.K., Tabi Z., Human cytomegalovirus inhibits maturation and impairs function of monocyte-derived dendritic cells, Blood (2002) 99:2913-2921.
[44] Olin M.R., Batista L., Xiao Z., Dee S.A., Murtaugh M.P., Pijoan C.C., Molitor T.W., Gammadelta lymphocyte response to porcine reproductive and respiratory syndrome virus, Viral Immunol. (2005) 18:490-499.

[45] Penna A., Pilli M., Zerbini A., Orlandini A., Mezzadri S., Sacchelli L., et al., Dysfunction and functional restoration of $\mathrm{HCV}$-specific $\mathrm{CD} 8$ responses in chronic hepatitis $\mathrm{C}$ virus infection, Hepatology (2007) 45:588-601.

[46] Piriou-Guzylack L., Salmon H., Membrane markers of the immune cells in swine: an update, Vet. Res. (2008) 39:54.

[47] Pollara G., Speidel K., Samady L., Rajpopat M., McGrath Y., Ledermann J., et al., Herpes simplex virus infection of dendritic cells: balance among activation, inhibition, and immunity, J. Infect. Dis. (2003) 187:165-178.

[48] Sakaguchi S., Naturally arising CD4+ regulatory $\mathrm{T}$ cells for immunologic self-tolerance and negative control of immune responses, Annu. Rev. Immunol. (2004) 22:531-562.

[49] Samsom J.N., de Bruin T.G., Voermans J.J., Meulenberg J.J., Pol J.M., Bianchi A.T., Changes of leukocyte phenotype and function in the bronchoalveolar lavage fluid of pigs infected with porcine reproductive and respiratory syndrome virus: a role for CD8(+) cells, J. Gen. Virol. (2000) 81:497-505.

[50] Shimizu M., Yamada S., Kawashima K., Ohashi S., Shimizu S., Ogawa T., Changes of lymphocyte subpopulations in pigs infected with porcine reproductive and respiratory syndrome (PRRS) virus, Vet. Immunol. Immunopathol. (1996) 50:19-27.

[51] Silva-Campa E., Flores-Mendoza L., Resendiz M., Pinelli-Saavedra A., Mata-Haro V., Mwangi W., Hernandez J., Induction of T helper 3 regulatory cells by dendritic cells infected with porcine reproductive and respiratory syndrome virus, Virology (2009) 387:373-379.

[52] Suradhat S., Thanawongnuwech R., Poovorawan Y., Upregulation of IL-10 gene expression in porcine peripheral blood mononuclear cells by porcine reproductive and respiratory syndrome virus, J. Gen. Virol. (2003) 84:453-459.

[53] Thanawongnuwech R., Thacker E.L., Interleukin10 , interleukin-12, and interferon-gamma levels in the respiratory tract following Mycoplasma hyopneumoniae and PRRSV infection in pigs, Viral Immunol. (2003) 16:357-367.

[54] Unutmaz D., Pileri P., Abrignani S., Antigenindependent activation of naive and memory resting 
T cells by a cytokine combination, J. Exp. Med. (1994) 180:1159-1164.

[55] Vallbracht S., Unsold H., Ehl S., Functional impairment of cytotoxic $\mathrm{T}$ cells in the lung airways following respiratory virus infections, Eur. J. Immunol. (2006) 36:1434-1442.

[56] Van Reeth K., Labarque G., Nauwynck H., Pensaert M., Differential production of proinflammatory cytokines in the pig lung during different respiratory virus infections: correlations with pathogenicity, Res. Vet. Sci. (1999) 67:47-52.

[57] Visser N., Lütticken D., Vaccination and control of Aujeszky's disease, Dordrecht, Kluwer Academic, 1989 , p. 37.

[58] Wang X., Eaton M., Mayer M., Li H., He D., Nelson E., Christopher-Hennings J., Porcine reproductive and respiratory syndrome virus productively infects monocyte-derived dendritic cells and compromises their antigen-presenting ability, Arch. Virol. (2007) 152:289-303.

[59] Wensvoort G., Terpstra C., Pol J.M., ter Laak E.A., Bloemraad M., de Kluyver E.P., et al., Mystery swine disease in The Netherlands: the isolation of Lelystad virus, Vet. Q. (1991) 13:121-130.

[60] Wensvoort G., Lelystad virus and the porcine epidemic abortion and respiratory syndrome, Vet. Res. (1993) 24:117-124.
[61] Wherry E.J., Blattman J.N., Murali-Krishna K., van der Most R., Ahmed R., Viral persistence alters CD8 T-cell immunodominance and tissue distribution and results in distinct stages of functional impairment, J. Virol. (2003) 77:4911-4927.

[62] Wills R.W., Doster A.R., Galeota J.A., Sur J.H., Osorio F.A., Duration of infection and proportion of pigs persistently infected with porcine reproductive and respiratory syndrome virus, J. Clin. Microbiol. (2003) 41:58-62.

[63] Xiao Z., Batista L., Dee S., Halbur P., Murtaugh M.P., The level of virus-specific T-cell and macrophage recruitment in porcine reproductive and respiratory syndrome virus infection in pigs is independent of virus load, J. Virol. (2004) 78:5923-5933.

[64] Zajac A.J., Blattman J.N., Murali-Krishna K., Sourdive D.J., Suresh M., Altman J.D., Ahmed R., Viral immune evasion due to persistence of activated T cells without effector function, J. Exp. Med. (1998) 188:2205-2213.

[65] Zuckermann F.A., Garcia E.A., Luque I.D., Christopher-Hennings J., Doster A., Brito M., Osorio F., Assessment of the efficacy of commercial porcine reproductive and respiratory syndrome virus (PRRSV) vaccines based on measurement of serologic response frequency of gamma-IFN-producing cells and virological parameters of protection upon challenge, Vet. Microbiol. (2007) 123:69-85. 